\title{
Oral and Swallowing Abilities Test (Orsat) for Type 1 Sma Patients: Development and Application of a New Module.
}

\section{Beatrice Berti}

Policlinico Universitario Agostino Gemelli

\section{Lavinia Fanelli}

Policlinico Universitario Agostino Gemelli

\section{Roberto de Sanctis}

Policlinico Universitario Agostino Gemelli

\section{Roberta Onesimo}

Policlinico Universitario Agostino Gemelli

\section{Giorgia Coratti}

Policlinico Universitario Agostino Gemelli

\section{Concetta Palermo}

Policlinico Universitario Agostino Gemelli

\section{Daniela Leone}

Policlinico Universitario Agostino Gemelli

\section{Sara Carnicella}

Policlinico Universitario Agostino Gemelli

\section{Giulia Norcia}

Policlinico Universitario Agostino Gemelli

Nicola Forcina

Policlinico Universitario Agostino Gemelli

\section{Valentina Giorgio}

Policlinico Universitario Agostino Gemelli

Antonella Cerchiari ST

Ospedale Pediatrico Bambino Gesu

\section{Simona Lucibello}

Policlinico Universitario Agostino Gemelli

\section{Richard S. Finkel}

Saint Jude Children's Research Hospital

\section{Marika Pane}

Policlinico Universitario Agostino Gemelli

Eugenio Mercuri ( $\nabla$ eugeniomaria.mercuri@policlinicogemelli.it ) 


\section{Research}

Keywords: Spinal Muscular Atrophy, Swallowing, Dysphagia, Oral motor function

Posted Date: May 20th, 2020

DOl: https://doi.org/10.21203/rs.3.rs-29904/v1

License: (c) (i) This work is licensed under a Creative Commons Attribution 4.0 International License. Read Full License 


\section{Abstract}

Background: Swallowing is one of the most important aspects in the care of type 1 spinal muscular atrophy.

Main text:The aim of this paper is to describe the development of a new tool specifically designed to record different aspects related to oral abilities, swallowing and feeding in young type1 SMA patients. We also report its application to a cohort of type 1 infants to identify possible changes during the first 24 months of life. The new tool includes a checklist with 12 questions for carers and a classification of levels of impairment.

The scale was retrospectively used in 24 type 1 patients ( 8 females and 16 males,age range from 2.3 to 24.1 months (average age: 10.8 months), classified according to the Dubowitz's decimal classification into $1.1(n=8) ; 1.5(n=8) ; 1.9(n=8)$. There was a significant difference among the 3 subtypes both at baseline and at follow up $(p<0.001)$. Type 1 infants had very low scores from the age of 3 months and a rapid deterioration already by 6 months; type 1.5 infants had a more variable progression but by 9 months $80 \%$ had the lowest scores. Patients with type 1.9 had better scores until the age of 1 year and had an overall better outcome.

Conclusion: Our results suggest that the new tool may help to routinely capture changes over time in type 1 infants and that the trajectories of progression reflect the overall severity of the disease. The items assessing fatigue during the nursing sessions were the most frequently impaired even in infants who did not have any other obvious clinical sign of swallowing difficulties.

\section{Background}

Spinal Muscular Atrophy (SMA) is a neuromuscular disorder caused by mutations in the SMN1 gene leading to motor neuron loss and subsequent muscular atrophy and weakness. Classically SMA has been classified into three main subtypes based on age of onset and maximum function achieved(1). Type 1 SMA is the most severe form characterized by severe hypotonia, weakness and increasing respiratory, swallowing and feeding difficulties over time. As this form includes patients with different degree of severity, it has been proposed that type 1 SMA patients could be subdivided into three main subgroups: 1.1 , the more severe end of the spectrum with early, severely reduced mobility, respiratory and bulbar difficulties; 1.5 , the most common phenotype, with inability to raise the legs against gravity or to maintain the head posture but no overt feeding or respiratory difficulties at diagnosis; 1.9, the mildest phenotypes, infants may achieve head control $(2,3)$. The three subgroups grossly overlap with the subtypes $1 \mathrm{~A}, \mathrm{~B}$ and $C$, proposed in another classification more based on age of onset $(3,4)$.

Improvements in Standards of Care with the more systematic use of optimal respiratory care, including non-invasive ventilation, and better management of nutritional support have resulted in better survival in type 1 SMA in the last decade $(5,6)$. The advent of new therapeutical approaches has resulted in a further dramatic improvement in these patients, changing the natural history of the disease(7-10). So far, most 
of the attention has been focused on survival and functional motor outcome. Despite feeding being one of the most important aspects in the care of type 1 SMA, less has been reported about possible changes in swallowing and bulbar function in the treated patients. This is probably at least partly due to the paucity of available tools to assess these aspects. While there are a number of outcome measures specifically designed to assess motor function in weak infants, such as the CHOP INTEND(11), or scales assessing motor developmental milestones $(12,13)$ there are no dedicated tools for the assessment of swallowing and oral motor skills in type 1 SMA or in general, in weak young infants. One of the challenges in this age group, especially in the first year after birth, is that the level of abilities increases with age, with changes in feeding modalities and in the consistency of food texture(14). Also, the volume of food needs to increase as the child grows to provide adequate nutrition to support growth. As such, even in the absence of overt dysphagia there may be an element of oral-motor fatigue that precludes adequate caloric and fluid intake.

The few studies reporting chewing, swallowing and speech in SMA patients, with few exceptions, do not include or only include few type 1 infants(15-19). A very recent study used an observation list with feeding related issues and recorded different parameters during a feeding session(20). Another recent study used the Neuromuscular Disease Swallowing Status Scale, that has not been specifically designed for young infants(21), and in another study nutritional aspects were assessed as part of a survey(22).

In this paper we describe the development of a new tool specifically designed to record different aspects related to swallowing and feeding in type 1 SMA patients that could be easily used in a clinical setting in infants from the first months after birth until 24 months of age More specifically, we wished to describe i) the development of the scale, ii) to define how the scale follows possible changes in swallowing in type 1 SMA patients in relation to the overall severity of the disease and iii) to correlate possible changes in this scale with functional levels of swallowing.

\section{Main Text}

\section{Development of the scale}

The aim of our effort was to develop a scale that could be easily used in the clinical routine, not requiring expensive or invasive diagnostic tools, able to capture a number of aspects related to swallowing recorded using a structured format. As some of these aspects are likely to change over time, as part of the progression of the disease or following possible intervention, we also aimed to add an easy scoring system in an attempt to quantify the possible changes in the individual items. In order to do so we developed a checklist assessing individual aspects of swallowing or related to feeding or to the use of orofacial muscles; we also added a separate section summarizing the functional abilities into levels of impairment.

The checklist was based on our clinical experience including the questions that are routinely asked in our clinical setting by clinicians at each appointment as part of the clinical history but adding a more 
structured format and a scoring system.

As the aim was to develop a new tool, we also searched for possible additional items by performing a systematic review of similar tools used in SMA, with a comprehensive search of the following electronic databases: MEDLINE, CINAHL, PsycINFO, and EMBASE.

The primary search terms 'spinal muscular atrophy a 'neuromuscular disorder' were combined with keywords 'swallowing', 'feeding', 'dysphagia' and 'bulbar'. All electronic searches were limited to the English language and to publication years 1980 to 2020 .

The titles and abstracts of articles were screened by the first authors (LF, BB). As it was not always possible to ascertain details of the questionnaires from the abstract, we first identified all papers of interest and the full text of articles were then examined to obtain details. Only papers reporting tools used in type 1 were selected. Table 1 shows details of the papers reporting feeding/swallowing abilities in type 1 SMA. 
Table 1

Details of the papers reporting feeding/swallowing abilities in type 1 SMA.

\begin{tabular}{|c|c|c|c|c|}
\hline Reference & Study design & $\begin{array}{l}\text { Sample } \\
\text { size }\end{array}$ & Aim & Assessment \\
\hline $\begin{array}{l}\text { van der } \\
\text { Heul } \\
(2020)\end{array}$ & $\begin{array}{l}\text { Prospective } \\
\text { cohort }\end{array}$ & 16 & $\begin{array}{l}\text { To study feeding and swallowing problems } \\
\text { in type } 1 \text { SMA patients and their relation } \\
\text { with functional motor scores. }\end{array}$ & $\begin{array}{l}\text { Evaluation } \\
\text { during } \\
\text { feeding } \\
\text { session; } \\
\text { VFSS; CHOP } \\
\text { INTEND }\end{array}$ \\
\hline $\begin{array}{l}\text { Ah-Choi } \\
\text { et al. } \\
(2020)\end{array}$ & $\begin{array}{l}\text { Retrospective } \\
\text { cohort }\end{array}$ & 11 & $\begin{array}{l}\text { To evaluate the change in progressive } \\
\text { swallowing dysfunction from birth up to } \\
\text { years }\end{array}$ & NdSSS; VFSS \\
\hline $\begin{array}{l}\text { van der } \\
\text { Heul } \\
(2019)\end{array}$ & $\begin{array}{l}\text { Cross- } \\
\text { sectional }\end{array}$ & 11 & $\begin{array}{l}\text { To investigate self-reported bulbar } \\
\text { problems in patients with SMA and their } \\
\text { relationship to age }\end{array}$ & $\operatorname{DDD}(p) N M D$ \\
\hline $\begin{array}{l}\text { van den } \\
\text { Engel- } \\
\text { Hoek et } \\
\text { al. (2015) }\end{array}$ & $\begin{array}{l}\text { Systematic } \\
\text { Review }\end{array}$ & & & \\
\hline \multirow{4}{*}{$\begin{array}{l}\text { Wadman } \\
\text { et al. } \\
(2014)\end{array}$} & \multirow{4}{*}{$\begin{array}{l}\text { Cross- } \\
\text { sectional }\end{array}$} & \multirow[t]{4}{*}{11} & To evaluate: & \multirow{4}{*}{$\begin{array}{l}\text { Non- } \\
\text { standardized } \\
\text { questionnaire }\end{array}$} \\
\hline & & & $\begin{array}{l}\text { 1. Eating problems (difficulties with biting, } \\
\text { swallowing, and/or chewing). }\end{array}$ & \\
\hline & & & $\begin{array}{l}\text { 2. Dysphagia (occurring problems with } \\
\text { swallowing, i.e., problems moving food or } \\
\text { fluids from the oral cavity to the throat or } \\
\text { delayed passage of food or drinks through } \\
\text { the esophagus). }\end{array}$ & \\
\hline & & & $\begin{array}{l}\text { 3. Choking (blockage of the throat by food } \\
\text { or drinks). }\end{array}$ & \\
\hline $\begin{array}{l}\text { Davis et } \\
\text { al. }(2014)\end{array}$ & $\begin{array}{l}\text { Cross- } \\
\text { sectional }\end{array}$ & 44 & $\begin{array}{l}\text { To provide a current snapshot of the } \\
\text { nutritional practices of children with SMA } \\
\text { type I. }\end{array}$ & $\begin{array}{l}\text { Non- } \\
\text { standardized } \\
\text { questionnaire }\end{array}$ \\
\hline $\begin{array}{l}\text { Durkin et } \\
\text { al. }(2008)\end{array}$ & $\begin{array}{l}\text { Retrospective } \\
\text { cohort }\end{array}$ & 9 & $\begin{array}{l}\text { To assess the risks and benefits of early } \\
\text { referral anti-reflux procedure shortly after } \\
\text { diagnosis of SMA type I. }\end{array}$ & VFSS \\
\hline
\end{tabular}

No scale appeared to be specifically designed for type 1 SMA and most of the items included were either similar to those we had already included or were not suitable for the construct of our scale that was designed as a checklist rather than an observer rated scale.

We initially also explored the possibility to add items generally recorded by the speech therapists, that could record the child's behavior during the observation of a meal when the family came for their routine assessments. The original idea was to develop a scale, similar to the Egen Klassification scale(23), that 
could combine patient reported and observer rated items. We therefore included measurements of heart rate and of 02 saturation during a meal but, after piloting the scale, the analysis of the data showed that the two items were often concordant and were also concordant with item assessing fatigue and duration of the meal and, at the same time, added a level of complexity that was beyond the scope of our scale. These items, even though important as part of the speech therapist assessment, were not included in the final version. Furthermore, as many families reported that there was a lot of variability among meals and that the observation in clinic did not always reflect other aspects that were observed at home, we decided to keep the design of the scale as a checklist/questionnaire as this could be more easily used in different settings. We therefore also excluded items or additional investigations such as video-fluoroscopy, that should be specifically managed by speech therapists or other trained specialists. In contrast, following increasing evidence of treated infants showing an improvement in speech, rarely present in untreated type 1 infants, we added two items exploring the ability to produce syllables in the first months or clear words around one year and beyond. These items were meant to record the use of orofacial muscles and, more generally, of the strength of the child to be able to produce sounds and to articulate words rather than as a neurodevelopmental measure of speech and comprehension.

The final version of the scale includes 12 items assessing swallowing and oral skills that were thought to be clinically meaningful for type 1 SMA population and developmentally appropriate for infants since the first months of age (0-5, 6-9 and 10-24 months) (Table 2). After the final version was designed, we also conducted interviews with individual caregivers and focus groups with caregivers of type 1 infants who confirmed that all the activities included were clinically meaningful for the families.

\section{Scoring system}

The main caregiver, generally the mother, is asked structured questions to assess the different aspects related to the feeding/swallowing behavior of the child. The responses can be graded by using a simple scoring system. Each item is scored as 0 or 1 depending if the child is able or unable to perform the activity (Table 2). As some items are age dependent, the maximal score changes with increasing age. In the infants younger than 6 months who cannot be assessed on swallowing semisolids or solids the maximum score is 7 while in those between 6 and 9 months, who can also be assessed on semiliquids/semisolids the maximum score is 10 . For infants 10 months or older who can be assessed for all food consistencies including solids, the maximum total score is 12 .

An additional separate section was added to define levels of feeding/swallowing impairment. This was loosely based on the criteria used in the American Speech-Language-Hearing Association National Outcomes Measurement System (ASHA NOMS)(24), a multidimensional instrument assessing the supervision required for feeding and the type of diet. Our classification was much simpler and using level of impairment rather than abilities and was simplified for general use both by reducing the number of levels as some were not relevant for our age group and excluding activities that could only be collected by speech therapists or trained professionals and not be easily assessed in a patient reported tool(24).

Functional levels were classified as follows: 


\section{No impairment}

the individual's ability to eat is not limited by swallow function. Swallowing is reported as safe and efficient for all consistencies (when age appropriate), without choking episodes or other clinical signs such as retching or cough.

\section{Mild impairment}

swallowing is safe, but usually requires moderate cues to use compensatory strategies or more careful posturing or other intervention (thickening food or other edit in texture).

\section{Moderate impairment}

swallowing for thin liquids is safe but the infant gets easily tired and unable to complete a full meal and takes less than $50 \%$ of nutrition and hydration by mouth. These children may require need for oral supplements or tube feeding (NG tube or G-tube).

\section{Severe impairment}

individual is not able to swallow anything safely by mouth. All nutrition and hydration is received through non-oral means (e.g. nasogastric or G-tube). The functional levels assessed are scored separately from the checklist. (Table 2) 
Table 2

OrSAT checklist.

\begin{tabular}{|c|c|c|c|c|c|c|}
\hline \multirow[b]{2}{*}{ Score* } & \multicolumn{2}{|c|}{$0-5 \mathrm{~m}$} & \multicolumn{2}{|c|}{$6-9 m$} & \multicolumn{2}{|c|}{$10-24 \mathrm{~m}$} \\
\hline & 1 & 0 & 1 & 0 & 1 & 0 \\
\hline $\begin{array}{l}\text { 1. Able to swallow thin liquids } \\
\text { (for example: milk, water) }\end{array}$ & $\mathrm{Y}$ & $\mathrm{N}$ & Y & $\mathrm{N}$ & Y & $\mathrm{N}$ \\
\hline $\begin{array}{l}\text { 2. Able to swallow semi liquids } \\
\text { (for example: yogurt, pureed fruits } \\
\text { and vegetables) }\end{array}$ & & & Y & $\mathrm{N}$ & Y & $\mathrm{N}$ \\
\hline $\begin{array}{l}\text { 3. Able to swallow semisolids } \\
\text { (for example: rice cereal, mashed } \\
\text { banana, cooked egg) }\end{array}$ & & & Y & $\mathrm{N}$ & Y & $\mathrm{N}$ \\
\hline $\begin{array}{l}\text { 4. Able to swallow solids } \\
\text { (requires chewing and then } \\
\text { swallowing, for example: meat, apple } \\
\text { pieces) }\end{array}$ & & & & & Y & $\mathrm{N}$ \\
\hline Score & 1 & & & & 0 & \\
\hline 5. Need for intervention & & eed $t$ & nte & ation & $\begin{array}{l}\mathrm{Ne} \\
\mathrm{oth} \\
\mathrm{op}\end{array}$ & dion \\
\hline $\begin{array}{l}\text { 6. Cough/signs of stagnation during } \\
\text { meal }\end{array}$ & & natio & 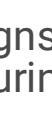 & neal & & stagnation \\
\hline 7. Able to swallow without tiring & & to si & & hout & & $\begin{array}{l}\text { but easily tired, } \\
\text { riodically during }\end{array}$ \\
\hline 8. Able to complete a meal & $\mathrm{Ab}$ & to $\mathrm{cc}$ & The & meal & Un & lete a meal \\
\hline $\begin{array}{l}\text { 9. Duration of main meals ( }<45 \mathrm{~min} \\
\text { for semisolids and } 25 \mathrm{~min} \text { for } \\
\text { breastfeeding) }\end{array}$ & & $\min _{25 \mathrm{~m}}$ & & olids & Lor & \\
\hline $\begin{array}{l}\text { 10. Need for Suctioning during } \\
\text { mealtime }\end{array}$ & $\begin{array}{l}\text { No } \\
\text { dul }\end{array}$ & $\begin{array}{l}\text { eed } \\
g \mathrm{me}\end{array}$ & & ing & $\begin{array}{l}\mathrm{Ne} \\
\mathrm{me}\end{array}$ & hing during \\
\hline $\begin{array}{l}\text { 11. Able to speak one or more } \\
\text { syllables (if age }>6 \text { months) }\end{array}$ & Yes & & & & No & \\
\hline $\begin{array}{l}\text { 12. Able to speak correctly one or } \\
\text { more words (if age }>12 \text { months) }\end{array}$ & Yes & & & & No & \\
\hline
\end{tabular}

TOTAL SCORE _ 


\section{$0-5 \mathrm{~m} \quad 6-9 \mathrm{~m} \quad 10-24 \mathrm{~m}$}

\section{Levels of Impairment}

No impairment: the individual's ability to eat is not limited by swallow function. Swallowing is reported as safe and efficient for all consistencies (when age appropriate), without choking episodes or other clinical signs such as retching or cough.

Mild impairment: swallowing is safe, but usually requires moderate cues to use compensatory strategies or more careful posturing or other intervention (thickening food).

Moderate: swallowing for thin liquids is safe but the infant gets easily tired and unable to complete a full meal and takes less than $50 \%$ of nutrition and hydration by mouth. These children may require need for oral supplements or alternative method of feeding (NG tube or G-tube).

Severe: individual is not able to swallow anything safely by mouth. All nutrition and hydration is received through non-oral means (e.g. nasogastric or G-tube).

The checklist and the functional levels were piloted in 60 typically developing infants of age between 3 and 24 months. Less than $5 \%$ of the typically developing infants had a score of 0 on individual items and always only in one item of the checklist. The items that were found to have occasional scores of 0 were those assessing choking and duration of the meal. The maximal functional score was generally the full score according to the age and in less than $5 \%$ the total scores were different but within one point only from the age appropriate maximum score. When the levels of impairment were assessed, more than $95 \%$ of the children had a normal level and less than $5 \%$ had a level labelled as mild impairment as they required some posture or texture modifications generally related to gastroesophageal reflux.

The scale was also administered at a distance of 5 to 14 days in 10 typically developing and in 5 type 1 patients. The level of concordance was 0.98 .

Although the new tool was based on our previous routine assessment including the same questions than the checklist, the modality of data collection used in the past was less structured. In order to establish whether the new scoring system could be applied to the data routinely collected over the last years, we investigated possible concordance between our previous routine assessment and the new structured approach using the checklist. The two methods were used independently by two examiners, each blind to the results of the other, to the same families on consecutive days, randomly starting with one or the other assessment. A correlation between the two tools showed a very high concordance in the responses (0.96).

\section{Application of the scale to a type 1 SMA cohort}

The checklist and the level assessment were retrospectively used in a cohort of 24 consecutive type 1 SMA patients (8 females and 16 males) admitted to our Center from January 2011 up to December 2016. All patients had a genetically confirmed diagnosis of SMA with homozygous deletion of exon 7 in the SMN1 gene and a clinically confirmed diagnosis of type 1 SMA. Infants were classified according to the Dubowitz's decimal classification( 2,10$){ }^{2,10}: 1.1$ (8 patients); 1.5 (8 patients); 1.9 (8 patients). 
Clinical data regarding feeding and swallowing were available on the clinical notes in all patients. As part of our clinical routine, all the information required were consistently collected asking questions similar to those used in the current scale even if not with an identical wording. As part of our routine, in agreement with care recommendations, type 1 patients are generally seen at least every 3 months until the age of one year and at least every 6 months after that.

\section{Statistical analysis}

The difference in baseline scores and progression in the 3 subgroups was calculated using the Kruskall Wallis test with level of significance set at 0.05 .

A correlation between the total scores obtained on the checklist and the functional levels was performed using correlation coefficient test.

\section{Results}

\section{OrSAT checklist}

The scores on the checklist ranged between 0 and 7 in the assessments performed before 6 months (mean: 3.43, SD: 2.15), between 0 and 10 in those performed between 6 and 10 months (mean: 3.16, SD: 3.64), and between 0 and 12 in those older than 10 months (mean: 5.39, SD: 4.38). Figure 1 shows individual details of the scores in the different subgroups according to severity.

\section{1}

All 8 patients had an assessment at 3 months. The total score was 0 in 2/8, 2 in 4/8, 3 in one and 4 in another one. The only items in which the scores were different from 0 were: able to swallow liquids, able to complete a meal and, even if less frequently, the items assessing the presence of cough or the need for suctioning.

By 6 months none of the surviving infants was able to swallow liquids and to complete a meal. All had a score of 0 in all items. Figure 1 shows details of the individual changes.

\section{5}

All 8 patients had an assessment at 3 months. The total score was 3 in $2 / 8,4$ in $1 / 8,5$ in 2/8, 6 in $1 / 8$ and 7 in $2 / 8$. The items assessing meal duration and tiredness during the nursing session were the most frequently impaired. By 6 months the scores had decreased in 7 of 8 infants in all items and by 9 months only two of the infants had a score respectively of 7 and 5 while all the others had 0 . Figure 1 shows details of the individual changes. 
Type 1.9 infants were generally assessed after 6 months. All 8 patients had an assessment at 9 months: the total score was more than 9 in 3/8, 8 in $4 / 8$ and 5 in one infant. Similar scores were seen at one year with only a few infants requiring intervention, tiring during the nursing session and showing a longer duration. Tiredness during the nursing session and duration of the mea/ were also the items most frequently impaired from 12 months onwards. At 24 months the total score was more than 9 in 4/8, 8 in 2/8, 2 in one and 1 in another one infant. Figure 1 shows details of the individual changes.

The difference between 1.1, 1.5 and 1.9 was significant both at baseline $(p<0,001)$ and when the follow up changes were considered $(p=0,001)$. Table 3 shows details of the mean scores for each individual item. 
Table 3

Mean scores for each individual item and visits subdivided by type 1 SMA decimal classification.

\begin{tabular}{|c|c|c|c|c|c|c|c|}
\hline \multirow{3}{*}{ Item } & \multirow{3}{*}{$\begin{array}{l}\text { SMA } \\
\text { Decimal } \\
\text { classification }\end{array}$} & \multicolumn{6}{|c|}{ OrSAT checklist Scores } \\
\hline & & $\begin{array}{l}3 \\
\text { months }\end{array}$ & $\begin{array}{l}6 \\
\text { months }\end{array}$ & $\begin{array}{l}9 \\
\text { months }\end{array}$ & $\begin{array}{l}12 \\
\text { months }\end{array}$ & $\begin{array}{l}18 \\
\text { months }\end{array}$ & $\begin{array}{l}24 \\
\text { months }\end{array}$ \\
\hline & & (Mean) & (Mean) & (Mean) & (Mean) & (Mean) & (Mean) \\
\hline Item 1 & 1.1 & 0.75 & 0.14 & 0 & $-\star$ & $-\star$ & -* \\
\hline \multirow{2}{*}{$\begin{array}{l}\text { Able to swallow } \\
\text { liquids }\end{array}$} & 1.5 & 1 & 0.75 & 0.25 & 0.2 & 0 & 0 \\
\hline & 1.9 & - & 1 & 1 & 1 & 0.75 & 0.75 \\
\hline Item 2 & 1.1 & NA & 0 & 0 & $-\star$ & $-\star$ & -* \\
\hline \multirow{2}{*}{$\begin{array}{l}\text { Able to swallow } \\
\text { semi liquids }\end{array}$} & 1.5 & NA & 0.375 & 0.125 & 0.2 & 0 & 0 \\
\hline & 1.9 & - & 1 & 1 & 1 & 0.875 & 0.75 \\
\hline Item 3 & 1.1 & NA & 0 & 0 & $-\star$ & -* & -* \\
\hline \multirow{2}{*}{$\begin{array}{l}\text { Able to swallow } \\
\text { semisolids }\end{array}$} & 1.5 & NA & 0.25 & 0 & 0 & 0 & 0 \\
\hline & 1.9 & - & 0.75 & 0.875 & 1 & 0.875 & 0.75 \\
\hline Item 4 & 1.1 & NA & NA & NA & $-\star$ & $-\star$ & -* \\
\hline \multirow{2}{*}{$\begin{array}{l}\text { Able to swallow } \\
\text { solids }\end{array}$} & 1.5 & NA & NA & NA & 0 & 0 & 0 \\
\hline & 1.9 & - & NA & NA & 0.25 & 0.5 & 0.625 \\
\hline Item 5 & 1.1 & 0 & 0 & 0 & $-\star$ & -* & -* \\
\hline \multirow{2}{*}{$\begin{array}{l}\text { Need for } \\
\text { intervention }\end{array}$} & 1.5 & 0.75 & 0.125 & 0.125 & 0 & 0 & 0 \\
\hline & 1.9 & - & 0.5 & 0.5 & 0.25 & 0.25 & 0.25 \\
\hline Item 6 & 1.1 & 0.25 & 0 & 0 & $-\star$ & $-\star$ & -* \\
\hline \multirow{2}{*}{$\begin{array}{l}\text { Cough/signs of } \\
\text { stagnation during } \\
\text { meal }\end{array}$} & 1.5 & 0.75 & 0.25 & 0.25 & 0.2 & 0 & 0 \\
\hline & 1.9 & - & 0.75 & 0.75 & 0.75 & 0.625 & 0.625 \\
\hline Item 7 & 1.1 & 0 & 0 & 0 & $-\star$ & $-\star *$ & -* \\
\hline \multirow{2}{*}{$\begin{array}{l}\text { Able to swallow } \\
\text { without tiring }\end{array}$} & 1.5 & 0.375 & 0.125 & 0.125 & 0 & 0 & 0 \\
\hline & 1.9 & - & 0.75 & 0.625 & 0.5 & 0.5 & 0.5 \\
\hline Item 8 & 1.1 & 0.5 & 0.14 & 0 & $-\star$ & $-\star$ & -* \\
\hline $\begin{array}{l}\text { Able to complete } \\
\text { a meal }\end{array}$ & 1.5 & 0.875 & 0.5 & 0.125 & 0 & 0 & 0 \\
\hline
\end{tabular}

Key to legend: NA: not available; *: death; -: not evaluated 


\begin{tabular}{|c|c|c|c|c|c|c|c|}
\hline & 1.9 & - & 1 & 1 & 1 & 0.625 & 0.625 \\
\hline Item 9 & 1.1 & 0 & 0 & 0 & $-\star$ & $-\star$ & -* \\
\hline \multirow{2}{*}{$\begin{array}{l}\text { Duration of main } \\
\text { meals }\end{array}$} & 1.5 & 0.25 & 0.25 & 0.25 & 0.2 & 0 & 0 \\
\hline & 1.9 & - & 0.5 & 0.625 & 0.5 & 0.375 & 0.375 \\
\hline Item 10 & 1.1 & 0.375 & 0 & 0 & $-*$ & $-\star$ & -* \\
\hline \multirow{2}{*}{$\begin{array}{l}\text { Need for } \\
\text { suctioning during } \\
\text { mealtime }\end{array}$} & 1.5 & 1 & 0.625 & 0.25 & 0 & 0 & 0 \\
\hline & 1.9 & - & 1 & 1 & 1 & 0.75 & 0.75 \\
\hline Item 11 & 1.1 & NA & 0 & 0 & -* & $-*$ & -* \\
\hline \multirow{2}{*}{$\begin{array}{l}\text { Able to speak > } 1 \\
\text { syllable }\end{array}$} & 1.5 & NA & 0 & 0 & 0.2 & 0.25 & 0.25 \\
\hline & 1.9 & - & 0.25 & 0.875 & 1 & 1 & 1 \\
\hline Item 12 & 1.1 & NA & NA & NA & $-\star$ & $-\star$ & -* \\
\hline \multirow{2}{*}{$\begin{array}{l}\text { Able to speak } \\
\text { correctly > } 1 \text { word }\end{array}$} & 1.5 & NA & NA & NA & 0 & 0 & 0 \\
\hline & 1.9 & - & NA & NA & 0.5 & 0.875 & 0.875 \\
\hline
\end{tabular}

\section{Levels of impairment}

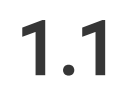

Seven of the 8 patients had a moderate or severe impaired swallowing by 3 months of age. By 6 months all of the surviving ones had severe impairment. Figure 2 shows change in levels of impairment at each visit in the study cohort.

\section{5}

Six of the 8 patients had no impairment $(n=3)$ or only mild impairment $(n=3)$ and none had severe involvement by 3 months with a progressive deterioration over time. Figure 2 shows change in levels of impairment at each visit in the study cohort.

\section{9}

Before the age of 9 months all the patients who had been diagnosed and could be assessed had no impairment. At 9 months 7 of the 8 had no impairment and 1 had mild impairment. Moderate or severe 
involvement occurred only in 2 patients by 18 months. Figure 2 shows change in levels of impairment at each visit in the study cohort.

\section{Correlation between scores and functional levels}

In infants below the age of 6 months, in whom the possible maximum score on the checklist is 7 , all infants independently labeled as within normal level had scores of 6 and 7, those with mild impairment had scores of 4 and 5, those with moderate impairment had scores of 2 and 3 and those with severe impairment all had a score of 0 . The correlation coefficient was 0.984 .

In infants between 6 and 9.99 months, in whom the possible maximum score on the checklist is 10, all infants with normal level had scores between 7 and 10, those with mild impairment had scores of 5 , those with moderate impairment had scores of 3 and those with severe impairment all had as a score of 0 . The correlation coefficient was 0.951 .

In infants between 10 months or older, in whom the possible maximum score on the checklist is 12, all infants with normal level had scores between 9 and 12, those with mild impairment had scores between 5 and 8 , those with moderate impairment had scores between 3 and 4 and those with severe impairment all had as a score of 0 . The correlation coefficient was 0.983 . Figure 3 shows correlation between scores and functional levels in study cohort.

\section{Correlation between functional levels and survival}

All 1.1 patients had a severe score at the visit prior to death and this was observed in 3 of the 41.5 patients who died before 24 months. None of the 1.9 patients died during the observation period.

\section{Discussion}

Dysphagia is classically one of the most critical aspects of care of type 1 SMA patients, who often present weakness affecting the various phases of feeding abilities, often involving not only the pharyngeal phase (decreased airway protection in combination with weak swallowing) but also sucking and handling of oral secretions(18). Both the first and the revised care recommendations $(5,6,25)$ highlight the importance of regular speech therapist assessments to monitor these aspects. The latest version of the care recommendations suggests to observe feedings and a careful evaluation of possible symptoms of dysphagia or other difficulties related to feeding $(5,6)$. For non-sitters, a swallow study is recommended shortly after diagnosis and, if the initial test is normal, closely monitored to detect possible early signs of feeding difficulties.

An effort has been made, at least in tertiary care centers, to implement regular clinical and radiological assessments in clinical practice, as they were not always routinely available for the lack of specialized speech and language therapists, physicians, and radiologists with interest and expertise in this field. As 
type 1 infants have very frequent visits to the centers for the administration of the new therapies and other assessments, there has been an increasing need to regularly collect structured information by mean of an easy clinical tool that could be easily updated at each appointment and used as a complement to the full speech therapist assessments performed at fixed intervals.

Despite the clinical relevance of dysphagia in type 1 infants, it is surprising how little effort there has been to develop disease specific tools aimed to identify different aspects of swallowing difficulties. Even in the recent trials, swallowing was not formally investigated with a structured assessment and was often defined by the need for tube feeding $(7,26)$. Only in the gene replacement trial the request to report the ability to swallow thin liquids was used(8).

We report the development of a new tool providing a simple assessment of swallowing in type 1 infants by using a checklist aimed to systematically record aspects of oral motor and swallowing function that are often assessed in clinical routine but not in a structured format. The checklist also provides the possibility to quantify the severity of impairment by using a very simple scoring system. The degree of severity was predictive of survival in the moderately and severely affected 1.1 and 1.5 patients. While this checklist is not meant to replace the more structured observer rated speech therapist assessment internationally recommended, it provides a measure of the parents' perception of their child's swallowing ability that also covers possible episodes occurring at home that may not be seen during a single observation in clinic. The use of patient reported measures has been strongly encouraged both by regulatory authorities both in Europe ('Reflection Paper on the Regulatory Guidance for the use of Health Related Quality of Life (HRQL) Measures in the Evaluation of Medicinal Products') and US (Guidance for Industry. Patient-Reported Outcome Measures: Use in Medical Product Development to Support Labeling Claims. US DHHS, FDA) as these tools can provide better understanding of the impact caused by disease and treatment on the patient.

Our checklist was developed using a template of questions that were routinely asked in our clinical setting, including two items assessing the oral motor aspects of language. While language was rarely observed in type 1 infants, following the advent of the new therapies there is an increasing number of patients in whom is possible to monitor their development of language over the first years. One of the challenges with developing an assessment for infants as young as newborns as well as infants in the first years after birth is that it should take into account age related changes, especially at the time when infants switch from a fully liquid diet to the introduction of new textures. Because of this, we defined age specific items and maximum possible scores for different ages.

We also designed a separate classification reporting functional levels, as a complement to the checklist, based on other tools used in other disorders and in a wider age range, simplified for the exclusive use in young infants in a clinical setting.

In order to explore the ability of the checklist and of the functional levels to detect possible changes over time in type 1, we retrospectively applied these tools to a cohort of type 1 infants longitudinally followed in our Unit. The results show very clear separation in swallowing abilities among infants with different 
severity of SMA, both at baseline and at follow up $(p<0.01)$. Infants with the most severe form, nearly invariably had some swallowing difficulties. Their follow up showed that already by six months, in all the survivor there was the indication for tube feeding. All but one had a score of zero at all time points and only at three months very few infants were able to swallow liquids even though they tired very easily and required compensatory postures and liquid thickening. Even in those with relatively better scores there was already an indication for introducing tube feeding.

At the other end of the spectrum, infants with type 1.9 not only had high scores at the time of diagnosis, that was often after 3 months, but had an increase in their total scores with increasing age, often reaching the ceiling of the age appropriate maximum scores. Interestingly, despite the good scores, some of these infants still showed to be tired and had an increased duration of the nursing session time. There was also some 'delay' in the time when solid food was introduced as reflected by the changes in the scores related to this activity. Patients with the 'intermediate' type 1 phenotype, 1.5 , showed a more variable progression and most of them reached a score of 0 between 6 and 12 months. It is of note that in the first 6 months in most patients their carers do not report problems with swallowing liquids, chocking episodes or other concern, but often reported that the children tired easily during feeding and they often needed short and frequent meals. Tiredness and need for intervention often preceded more obvious difficulties requiring more structured intervention after the age of 6 months. These finding were quite consistent even in the milder type 1 , clearly indicating that they should be regularly assessed and discussed with families and other operators involved in the care of the patients.

The subdivision of our cohort into clinical subtypes allowed a more precise definition of the trajectories and to reduce the variability reported in previous studies. A recent study, using the Neuromuscular Disease Swallowing Status Scale Scores (NDSSS) and videofluoroscopic swallowing studies in type 1 infants in the first 2 years, reported that on average swallowing function deteriorated at 6 months but with a a large variability of the time when tube feeding was needed(21). A previous survey in type 1 patients with a wider age range also reported similar variability but with an average age of feeding tube placement of 11 months(22).

Not surprisingly, the checklist scores were associated with the functional levels that were independently recorded capturing other aspects, such as posturing or use of alternative ways of feeding, that are not captured in the checklist. By using the two tools together, we were able to establish which checklist total scores were associated with each level in the different age groups.

\section{Conclusion}

Our findings suggest that the two tools may help to capture changes over time in type 1 infants and that, in addition to the items assessing choking and possible unsafe swallowing, particular attention should be paid to those assessing fatigue during the nursing session, as this was the most frequent finding even in infants who did not have any other obvious sign of swallowing difficulties. These results are in agreement with a recent study using a more structured observer rated approach who also showed that 
shortened nursing sessions were extremely frequent. Our findings confirmed that these aspects should be systematically explored with specific questions as parents often increase the frequency of feeding to compensate the short duration of nursing sessions, underestimating the importance of these findings.

One of the limitation of our study is that the application to the type 1 cohort was based on retrospective data. The current checklist was based on our template of questions routinely used in clinical practice, but we cannot exclude differences in wording or a variability that may be reduced using the more structured format present in the checklist. While we would have ideally started a new data collection to prospectively establish the possible changes and natural history of swallowing abilities, at the time we develop the final version, all our type I patients were on treatment with Nusinersen or in clinical trials. The only chance to observe possible changes in untreated patients was therefore to use the recent retrospective data. In order to understand possible major differences between the not structured format used in the past and the current checklist, we prospectively administered both in a small sample of patients. The results showed a good concordance suggesting that, even if with caution, the results obtained in the retrospective cohort could be used as a reference.

Further work is needed to complete the validation of the new tool and to fully explore its possible use in clinical and research settings. In our study the checklist was always performed by a clinical examiner interviewing the carers and further work is required to establish the reliability of the tool as a selfadministered patient reported measure.

Further studies exploring the new tool, also in relation to the more structured and complete assessments performed by speech therapists, will provide additional information on the sensitivity of this new tool as a routine screening tool. Our preliminary results suggest that our structured examination reporting parents' perception could be potentially used at each clinical appointment to provide some general information, especially when time and resources for more structured assessments are limited.

\section{Abbreviations}

SMA

Spinal muscular atrophy

SMN1

Survival of Motor Neuron 1

CHOP INTEND

Children's Hospital of Philadelphia Infant Test of Neuromuscular Disorders

OrSAT

Oral and Swallowing Abilities Test

ASHA NOMS

American Speech-Language-Hearing Association National Outcomes Measurement System

VFSS

VideoFluoroscopic Swallow Study

Page 18/24 
NdSSS

Neuromuscular Disease Swallowing Status Scale

\section{Declarations}

Funding

This research received no specific grant from any funding agency in the public, commercial or not-forprofit sectors.

\section{Ethics Committee Agreement}

The study is part of a larger natural history study on SMA approved by the Ethics Committee of our Institution (CEG1032218/08), and fully informed consent from the parents of participant was obtained before the study.

\section{Consent for publication}

Not applicable

\section{Availability of data and materials}

Individual data are shown in tables and figures. The datasets generated and/or analyzed during the current study are available from the corresponding author on reasonable request

\section{Competing interests}

Eugenio Mercuri has received funding as a member of advisory boards for SMA studies for AveXis, Biogen, lonis Pharmaceuticals, Inc., Novartis, and Roche; principal investigator for ongoing lonis Pharmaceuticals, Inc./Biogen and Roche clinical trials; funding from Famiglie SMA Italy, Italian Telethon, and SMA Europe.

Giorgia Coratti received funding from Biogen, Roche, Avexis and Genesis Pharma as speaker in sponsored symposia.

Roberto de Sanctis received funding from Biogen as speaker in sponsored symposia.

Marika Pane received funding as a member of advisory boards from Biogen and Avexis and as speaker in sponsored symposia. 
Richard S. Finkel Richard Finkel has received personal compensation for activities with lonis Pharmaceuticals, Biogen, AveXis, Capricor, Catabasis, Lilly, Roche, Novartis; and the SMA Foundation, SMA Europe and Cure SMA as a consultant or advisor. Dr. Finkel has received research support from lonis Pharmaceuticals, Biogen, Lilly, Cytokinetics Sarepta, NIH, MDA, and Summit.

Beatrice Berti, Lavinia Fanelli, Roberta Onesimo, Concetta Palermo, Daniela Leone, Sara Carnicella, Giulia Norcia, Nicola Forcina, Antonella Cerchiari, Valentina Giorgio, Simona Lucibello have nothing to disclose.

\section{Author's contributions}

BB, LF, MP, EM: Conceptualization, Formal Analysis, Investigation, Methodology, Writing Original Draft Preparation

RDS: Data Curation

RO, CP, DL: Data Curation, Formal Analysis, Investigation

GC: Data Curation, Formal Analysis, Methodology

SC, GN, NF, VG: Data Curation

AC: Conceptualization, Methodology

SL: Data Curation,Methodology

RSF: Data Curation,Methodology, Formal Analysis, Investigation

\section{Ackowledgements}

Not applicable

\section{References}

1. D'Amico A, Mercuri E, Tiziano FD, Bertini E. Spinal muscular atrophy. Orphanet J Rare Dis. 2011;6:71.

2. Dubowitz V. Chaos in the classification of SMA: a possible resolution. Neuromuscul Disord. 1995;5(1):3-5.

3. De Sanctis R, Pane M, Coratti G, Palermo C, Leone D, Pera MC, et al. Clinical phenotypes and trajectories of disease progression in type 1 spinal muscular atrophy. Neuromuscul Disord. 2018;28(1):24-8. 
4. Finkel R, Bertini E, Muntoni F, Mercuri E, Group ESWS. 209th ENMC International Workshop: Outcome Measures and Clinical Trial Readiness in Spinal Muscular Atrophy 7-9 November 2014, Heemskerk, The Netherlands. Neuromuscul Disord. 2015;25(7):593-602.

5. Mercuri E, Finkel RS, Muntoni F, Wirth B, Montes J, Main M, et al. Diagnosis and management of spinal muscular atrophy: Part 1: Recommendations for diagnosis, rehabilitation, orthopedic and nutritional care. Neuromuscul Disord. 2018;28(2):103-15.

6. Finkel RS, Mercuri E, Meyer OH, Simonds AK, Schroth MK, Graham RJ, et al. Diagnosis and management of spinal muscular atrophy: Part 2: Pulmonary and acute care; medications, supplements and immunizations; other organ systems; and ethics. Neuromuscul Disord. 2018;28(3):197-207.

7. Finkel RS, Mercuri E, Darras BT, Connolly AM, Kuntz NL, Kirschner J, et al. Nusinersen versus Sham Control in Infantile-Onset Spinal Muscular Atrophy. N Engl J Med. 2017;377(18):1723-32.

8. Mendell JR, Al-Zaidy S, Shell R, Arnold WD, Rodino-Klapac LR, Prior TW, et al. Single-Dose GeneReplacement Therapy for Spinal Muscular Atrophy. N Engl J Med. 2017;377(18):1713-22.

9. Pane M, Coratti G, Sansone VA, Messina S, Bruno C, Catteruccia M, et al. Nusinersen in type 1 spinal muscular atrophy: Twelve-month real-world data. Ann Neurol. 2019;86(3):443-51.

10. Pechmann A, Langer T, Schorling D, Stein S, Vogt S, Schara U, et al. Evaluation of Children with SMA Type 1 Under Treatment with Nusinersen within the Expanded Access Program in Germany. J Neuromuscul Dis. 2018;5(2):135-43.

11. Glanzman AM, McDermott MP, Montes J, Martens WB, Flickinger J, Riley S, et al. Validation of the Children's Hospital of Philadelphia Infant Test of Neuromuscular Disorders (CHOP INTEND). Pediatr Phys Ther. 2011;23(4):322-6.

12. Haataja L, Mercuri E, Regev R, Cowan F, Rutherford M, Dubowitz V, et al. Optimality score for the neurologic examination of the infant at 12 and 18 months of age. J Pediatr. 1999;135(2 Pt 1):15361.

13. De Sanctis R, Coratti G, Pasternak A, Montes J, Pane M, Mazzone ES, et al. Developmental milestones in type I spinal muscular atrophy. Neuromuscul Disord. 2016;26(11):754-9.

14. Cichero JA, Lam P, Steele CM, Hanson B, Chen J, Dantas RO, et al. Development of International Terminology and Definitions for Texture-Modified Foods and Thickened Fluids Used in Dysphagia Management: The IDDSI Framework. Dysphagia. 2017;32(2):293-314.

15. van der Heul AMB, Wijngaarde CA, Wadman RI, Asselman F, van den Aardweg MTA, Bartels B, et al. Bulbar Problems Self-Reported by Children and Adults with Spinal Muscular Atrophy. J Neuromuscul Dis. 2019;6(3):361-8.

16. Messina S, Pane M, De Rose P, Vasta I, Sorleti D, Aloysius A, et al. Feeding problems and malnutrition in spinal muscular atrophy type II. Neuromuscul Disord. 2008;18(5):389-93.

17. Wadman RI, van Bruggen HW, Witkamp TD, Sparreboom-Kalaykova SI, Stam M, van den Berg LH, et al. Bulbar muscle MRI changes in patients with SMA with reduced mouth opening and dysphagia. Neurology. 2014;83(12):1060-6. 
18. van den Engel-Hoek L, de Groot IJ, de Swart BJ, Erasmus CE. Feeding and Swallowing Disorders in Pediatric Neuromuscular Diseases: An Overview. J Neuromuscul Dis. 2015;2(4):357-69.

19. Audag N, Goubau C, Toussaint M, Reychler G. Screening and evaluation tools of dysphagia in children with neuromuscular diseases: a systematic review. Dev Med Child Neurol. 2017;59(6):5916.

20. van der Heul AMB, Cuppen I, Wadman RI, Asselman F, Schoenmakers M, van de Woude DR, et al. Feeding and Swallowing Problems in Infants with Spinal Muscular Atrophy Type 1: an Observational Study. J Neuromuscul Dis. 2020.

21. Choi YA, Suh DI, Chae JH, Shin HI. Trajectory of change in the swallowing status in spinal muscular atrophy type I. Int J Pediatr Otorhinolaryngol. 2020;130:109818.

22. Davis RH, Godshall BJ, Seffrood E, Marcus M, LaSalle BA, Wong B, et al. Nutritional practices at a glance: spinal muscular atrophy type I nutrition survey findings. J Child Neurol. 2014;29(11):146772.

23. Steffensen BF, Lyager S, Werge B, Rahbek J, Mattsson E. Physical capacity in non-ambulatory people with Duchenne muscular dystrophy or spinal muscular atrophy: a longitudinal study. Dev Med Child Neurol. 2002;44(9):623-32.

24. American Speech-Language Hearing Association. NOMS:AmericanSpeechLanguageHearingAssociationNationalOutcome Measurement System. Adult Speech-Language Pathology training manual. Rockville:. 1998.

25. Wang CH, Finkel RS, Bertini ES, Schroth M, Simonds A, Wong B, et al. Consensus statement for standard of care in spinal muscular atrophy. J Child Neurol. 2007;22(8):1027-49.

26. Finkel RS, Chiriboga CA, Vajsar J, Day JW, Montes J, De Vivo DC, et al. Treatment of infantile-onset spinal muscular atrophy with nusinersen: a phase 2, open-label, dose-escalation study. Lancet. 2016;388(10063):3017-26.

\section{Figures}




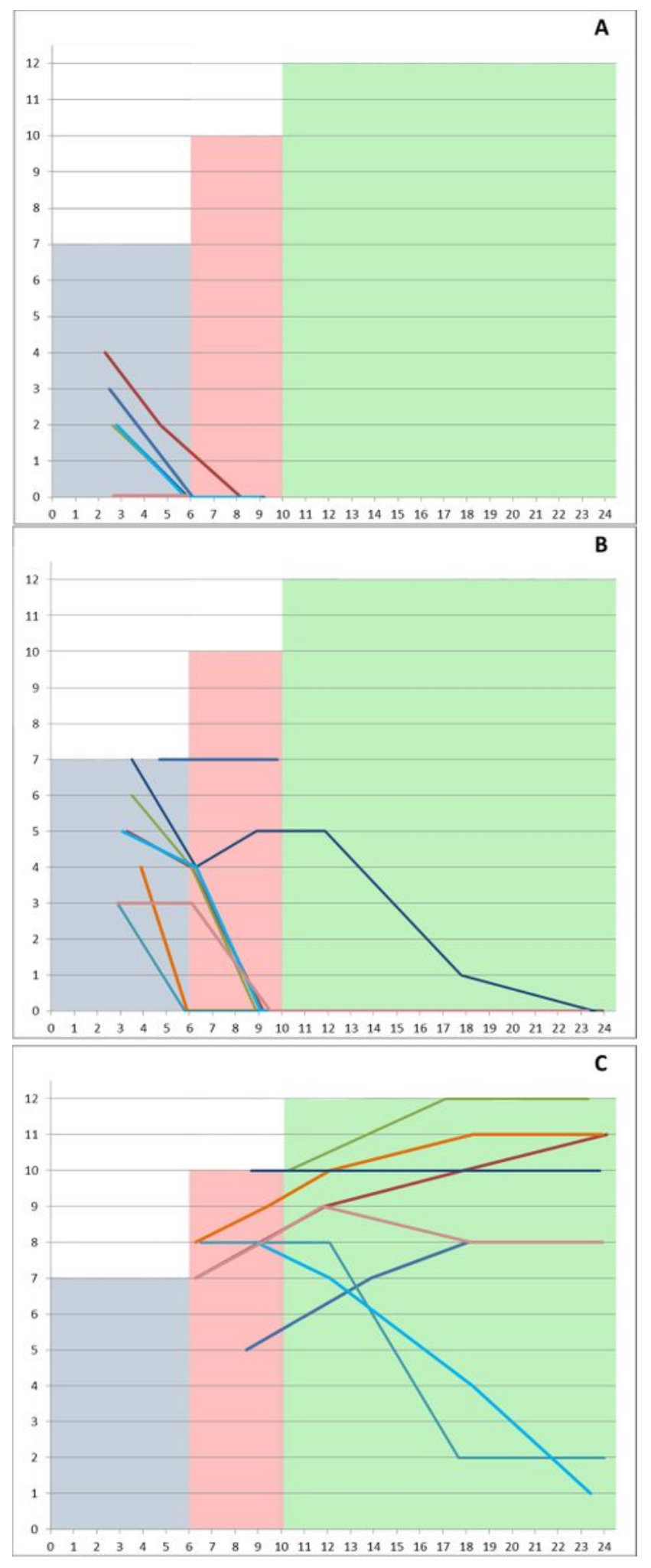

\section{Figure 1}

Individual details of the scores in the different subgroups according to severity highlighted by age range (0-5; 6-9;10-24 months). 


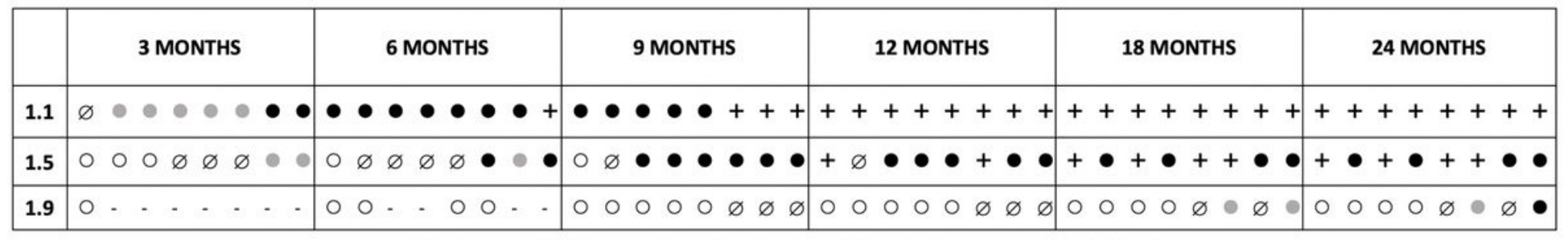

$\bigcirc$ No impairment; $\varnothing$ Mild impairment; $\bullet$ Moderate impairment; $\bullet$ Severe impairment; - Not evaluated; + Death

Figure 2

Change in levels of impairment in the study cohort subdivided by SMA 1 decimal classification and visits.

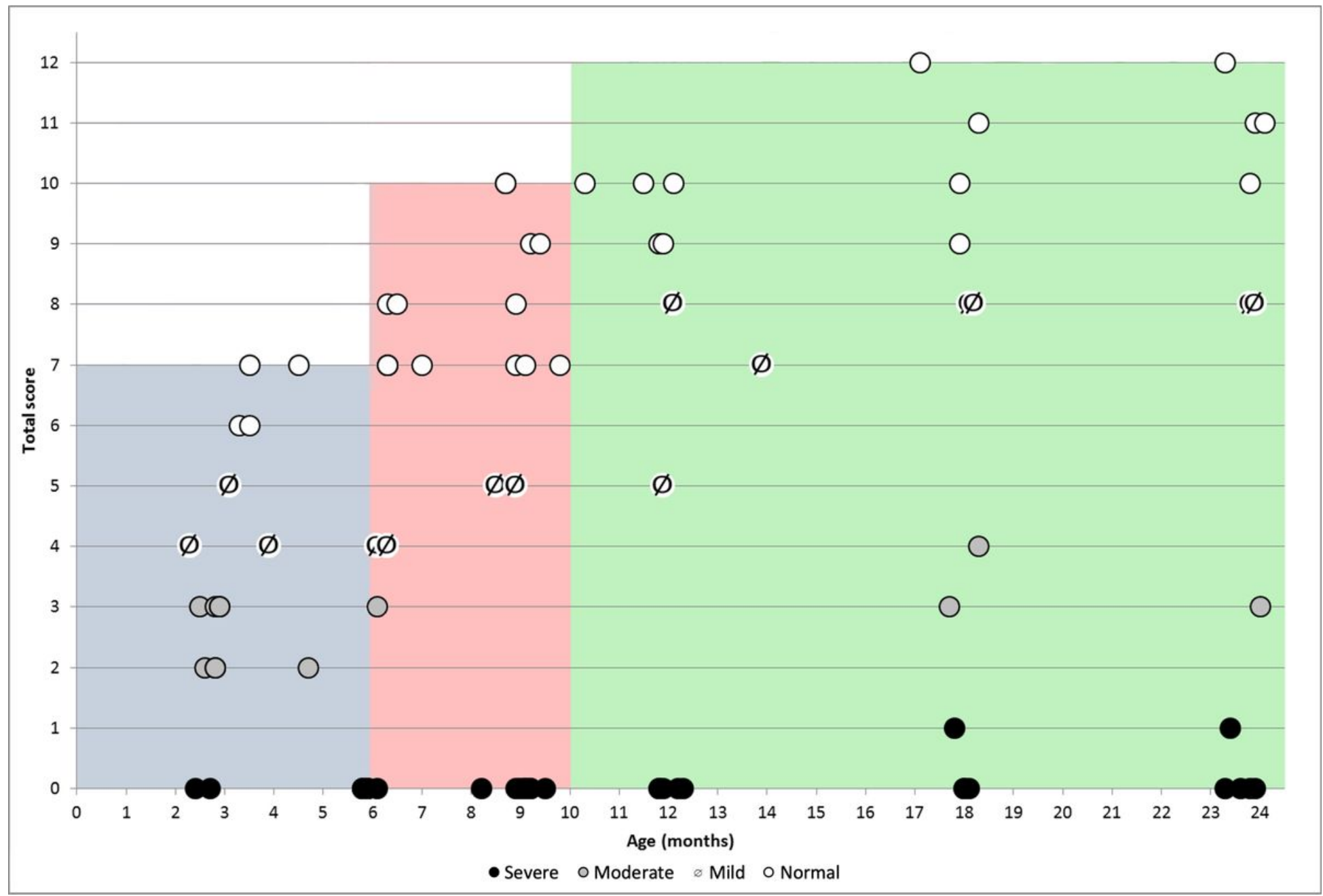

\section{Figure 3}

Correlation betweentotal scores and age in the different subgroups of severity, highlighted by age range (0-5; 6-9; 10-24 months). 